\title{
Oxytocin and Vasopressin Release in Discrete Brain Areas after Naloxone in Morphine-tolerant and -dependent Anesthetized Rats: Push-Pull Perfusion Study
}

\author{
J. A. Russell, ${ }^{1}$ I. Neumann, ${ }^{2}$ and R. Landgraf ${ }^{2}$ \\ 'Department of Physiology, University Medical School, Teviot Place, Edinburgh, EH8 9AG, United Kingdom and \\ ${ }^{2}$ Cell Biology and Regulation, Biological Sciences Section, University of Leipzig, Leipzig 7010, Germany
}

The effects of naloxone on the release of oxytocin and vasopressin in discrete brain areas were investigated in control and morphine-tolerant/dependent female rats anesthetized with urethane. Two or three consecutive push-pull perfusates were collected for $30-40 \mathrm{~min}$ each and the peptide contents measured by radioimmunoassay; naloxone $(5 \mathrm{mg} /$ kg, i.v.) was given after the first perfusion.

In control rats, naloxone did not increase oxytocin release from any of the regions studied: mediolateral septum, dorsal hippocampus, nucleus of tractus solitarius, or supraoptic nucleus. After naloxone, vasopressin release was approximately doubled in the nucleus of tractus solitarius $(p<0.05)$, indicating endogenous opioid inhibition of vasopressin release. Naloxone increased oxytocin concentration in the circulation 3.7 -fold $(p<0.001$ ) but did not affect vasopressin secretion.

In rats made morphine tolerant/dependent by intracerebroventricular infusion of morphine for $5 \mathrm{~d}$, oxytocin and vasopressin release in the perfused brain areas was initially similar to that in control rats, indicating tolerance to any initial morphine effects. In these rats, naloxone increased oxytocin release in the septum threefold relative to control rats $(p<$ 0.02 ) but did not alter oxytocin release in hippocampus or nucleus of tractus solitarius. Thus, the oxytocin neurons projecting to septum can develop morphine dependence and may be inhibited acutely by opioids acting via $\mu$-receptors. The results indicate morphine acts selectively on oxytocin neurons projecting to mediolateral septum compared with other central projection areas and compared with centrally projecting vasopressin neurons. In the supraoptic nucleus, naloxone increased oxytocin release 2.3-fold (from $9.2 \pm 3.1 \mathrm{pg} / 30 \mathrm{~min}$ ) and increased oxytocin release from axons of these neurons fivefold (from $7.8 \pm 3.2 \mathrm{pg} / 30 \mathrm{~min}$ ). Naloxone had no significant effect on vasopressin release from any of the central sites, or on vasopressin secretion into blood, although oxytocin secretion was increased 36 fold (from $17.2 \pm 2.6 \mathrm{pg} / \mathrm{ml} ; p<0.001$ ), confirming depen-

Received May 28, 1991; revised Oct. 18, 1991; accepted Oct. 23, 1991.

Mrs. R. Stephen, Ms. H. Hamilton (supported by a Scottish Home and Health Department Vacation Studentship), and Frau B. Wolff gave valuable technical assistance. This work was supported by the British Council and an IBRO/MacArthur Foundation Network Grant.

Correspondence should be addressed to Dr. J. A. Russell, Department of Physiology, University Medical School, Teviot Place, Edinburgh, EH8 9AG, United Kingdom.

Copyright (C) 1992 Society for Neuroscience $0270-6474 / 92 / 121024-09 \$ 05.00 / 0$ dence of magnocellular oxytocin neurons. The central processes of magnocellular supraoptic neurons may be a major source of central oxytocin released during morphine withdrawal.

In rats made morphine tolerant and dependent by intracerebroventricular morphine infusion for $5 \mathrm{~d}$, the precipitation of withdrawal by naloxone results in a large excitation of magnocellular oxytocin neurons and hypersecretion of oxytocin, with little effect on vasopressin secretion (Bicknell et al., 1988; Rayner et al., 1988). The content of oxytocin in cerebrospinal fluid (CSF) increases during morphine withdrawal, and at least some of this oxytocin may be released from the processes of centrally projecting oxytocin neurons (Jones et al., 1983; Robinson, 1983; Coombes et al., 1988). There are oxytocin-containing nerve terminals in several discrete brain areas (Sofroniew, 1983; Buijs et al., 1985; Sawchenko and Swanson, 1985), and oxytocin release can be stimulated from these terminals in a $\mathrm{Ca}^{2+}$-dependent and $\mathrm{K}^{+}$-stimulated manner (Buijs and van Heerikhuize, 1982; Landgraf et al., 1988). The major origin of these oxytocin terminals is parvocellular oxytocin-producing neurons in the paraventricular nucleus that do not project to the posterior pituitary gland (Buijs et al., 1985; Sawchenko and Swanson, 1985). From the posterior subdivision of the paraventricular nucleus, there is a projection to the nucleus of the tractus solitarius, and from the more rostral paraventricular nucleus subdivisions oxytocin ncurons project to mediolateral septum and dorsal hippocampus (Buijs, 1978; Swanson and Kuypers, 1980; Sofroniew, 1983; Neumann et al., 1988), although oxytocin neurons in the anterior commissural nucleus may project to septum (Caldwell et al., 1989). Centrally released oxytocin may be important in the initiation of maternal behavior in the immediate postpartum period (Van Leengoed et al., 1987) and in the facilitation of oxytocin secretion during suckling (Freund-Mercier et al., 1988). Radioimmunoassay of oxytocin content in pushpull perfusates of discrete brain areas has shown that oxytocin release during suckling or hyperosmotic stimulation in conscious rats is increased in the septum and hippocampus (Landgraf et al., 1988; Neumann and Landgraf, 1989). There are also centrally projecting vasopressin neurons (Buijs, 1978; Sofroniew, 1983), and some stimuli increase central release of both vasopressin and oxytocin (Landgraf et al., 1988), although other stimuli are selective for oxytocin (Neumann and Landgraf, 1989). Little is known of the chemical coding of pathways regulating these neurons, although endogenous opioids inhibit oxytocin but not vasopressin release in mediolateral septum during par- 
turition (Neumann et al., 1991). Monitoring changes in central oxytocin release during morphine withdrawal affords a means of investigating further whether opioids act on central oxytocin release since, in morphine dependence, withdrawal excitation provoked by naloxone represents a magnified mirror image of initial acute opiate actions (Bicknell et al., 1988; Rayner et al., 1988; Russell, 1989). Oxytocin and vasopressin are released in a $\mathrm{Ca}^{2+}$-dependent manner from central processes of magnocellular neurons, especially from their dendrites (Moos et al., 1984; Mason et al., 1986; Pow and Morris, 1989); oxytocin so released may be involved in some circumstances in further exciting oxytocin neurons themselves (Freund-Mercier and Richard, 1984; Yamashita et al., 1987; Moos et al., 1989).

We have thus studied with the push-pull perfusion technique the effects of naloxone in control and morphine-tolerant anesthetized rats, first, on the release of oxytocin in sites containing terminal fields of centrally projecting neurons, to assess opioid action on these neurons, and second, on the release of oxytocin within the supraoptic nucleus and from the axons of magnocellular oxytocin neurons. Vasopressin release was also measured.

Some of the results have been briefly reported previously (Russell et al., 1990).

\section{Materials and Methods}

Animals. Virgin female rats were used, of body weight approximately $250 \mathrm{gm}$ : Sprague-Dawley strain in Edinburgh for nucleus tractus solitarius studies; Wistar strain in Leipzig for the other studies. Rats were caged singly, fed pelleted food, given water ad libitum, and kept in the respective standard local conditions (see Landgraf et al., 1988; Rayner et al., 1988).

Surgical procedures. Five days before the terminal experiment, the rats were anesthetized with ether and a stainless steel 21 gauge cannula was implanted in the right lateral cerebral ventricle and connected via a Polythene cannula to a subcutaneous osmotic minipump to infuse either morphine $(10 \mu \mathrm{g} / \mathrm{hr}$ for $40 \mathrm{hr}$, then $20 \mu \mathrm{g} / \mathrm{hr}$ for $40 \mathrm{hr}$, and finally $50 \mu \mathrm{g} / \mathrm{hr}$ ) or vehicle $(1 \mu \mathrm{l} / \mathrm{hr}$ ), as fully described previously (Rayner et al., 1988). This procedure produces morphine tolerance and dependence within 5 d (Bicknell et al., 1988; Rayner et al., 1988; Russell, 1989; Pumford et al., 1991). At the same time, for subsequent push-pull perfusion, guide cannulas ( 21 gauge stainless steel) were stereotaxically implanted in the skull vault with the lower end on the dura; these cannulas were secured, like the intracerebroventricular cannula, with dental acrylic. Each rat was implanted with either one guide cannula for subsequent push-pull perfusion of left hippocampus ( $2 \mathrm{~mm}$ lateral to and $4 \mathrm{~mm}$ caudal to bregma, and $4.5 \mathrm{~mm}$ below the surface of the skull; see Landgraf et al., 1988; Neumann and Landgraf, 1989) or with two guide cannulas for simultaneous push-pull perfusion of right mediolateral septum $\left(5.5 \mathrm{~mm}\right.$ below bregma, $21^{\circ}$ from vertical; see Landgraf et al., 1988; Neumann and Landgraf, 1989) and either the left supraoptic nucleus $(1.7 \mathrm{~mm}$ lateral and $1.3 \mathrm{~mm}$ caudal to bregma, and $9.1 \mathrm{~mm}$ below the surface of the skull, after Paxinos and Watson, 1982) or among axons of the supraoptico-neurohypophysial tract (Armstrong et al., 1980), $1.6 \mathrm{~mm}$ lateral, $1.5 \mathrm{~mm}$ caudal to bregma, and $9.1 \mathrm{~mm}$ below skull surface.

Terminal experiments. On day 5 of intracerebroventricular morphine or vehicle infusion, the rats were anesthetized with urethane (ethyl carbamate, $1.25 \mathrm{gm} / \mathrm{kg}$, i.p.) and a femoral vein and artery were cannulated for drug injection and blood sampling as described previously (Rayner et al., 1988).

There were three push-pull perfusion experiments. In the first two experiments, the tip of the push-pull cannula was lowered to the required depth through the previously implanted guide cannula: in experiment 1 , into the dorsal hippocampus, and in experiment 2 one cannula was positioned in the mediolateral septum and the second in the vicinity of the supraoptic nucleus (see Fig. 5). In experiment 3, to perfuse the nucleus of tractus solitarius, the rat's head was immobilized, flexed, in a head-holder and the atlantooccipital membrane was exposed and incised to display the dorsal surface of medulla oblongata; the push-pull cannula, held in a micromanipulator, was lowered $0.5 \mathrm{~mm}$ beneath the surface of the medulla, $1.0 \mathrm{~mm}$ lateral to obex (see Landgraf et al., 1990); cerebrospinal fluid (CSF) was continually drained from cisterna magna with a filter paper wick. Push-pull perfusion was carried out at $20 \mu \mathrm{l} / \mathrm{min}(14 \mu \mathrm{l} / \mathrm{min}$ for nucleus of tractus solitarius), using artificial CSF (see Landgraf et al., 1988) delivered and collected by a pair of 1 $\mathrm{ml}$ glass syringes oppositely mounted on a slow infusion pump. The pull syringe contained $100 \mu \mathrm{l}$ of $0.2 \mathrm{M} \mathrm{HCl}$ to preserve peptides in the perfusate. Push-pull perfusion was started $2 \mathrm{hr}$ after completion of the surgical preparation. For push-pull perfusion of the nucleus of tractus solitarius, there were two consccutive perfusions cach of $40 \mathrm{~min}$, and for the hippocampus, mediolateral septum, and supraoptic nucleus there were three consecutive perfusions each of $30 \mathrm{~min}$. The pulled perfusates were stored frozen at $-20^{\circ} \mathrm{C}$ prior to extraction and radioimmunoassay of oxytocin and vasopressin content; the nucleus of tractus solitarius perfusates were lyophilized prior to extraction.

In each experiment, naloxone (naloxone $\mathrm{HCl}$, Sigma; $5 \mathrm{mg} / \mathrm{kg}, 10$ $\mathrm{mg} / \mathrm{ml} 0.9 \%$ saline) was injected intravenously at the end of the first push-pull perfusion.

Femoral arterial blood samples $(0.3 \mathrm{ml})$ were collected $5 \mathrm{~min}$ before the injection of naloxone and 5,30 , and $60 \mathrm{~min}$ after naloxone. The samples were immediately centrifuged, and the plasma separated, acidified, and stored at $-20^{\circ} \mathrm{C}$ prior to radioimmunoassay. The first blood sample was immediately replaced with $0.3 \mathrm{ml}$ of $0.9 \%$ saline injected intravenously, and subsequent samples werc replaced by the cells from the previous sample resuspended in $0.9 \% \mathrm{NaCl}$.

At the end of each experiment, the brain was removed and fixed in Bouin's fluid, and then frontal $60 \mu \mathrm{m}$ sections were cut in a Vibratome through the appropriate brain regions to check the position of the tip of the push-pull cannula. Some sections were used as negatives to produce positive prints of typical push-pull perfusion sites (see Fig. 5). Animals with correctly located cannulas were decided before the radioimmunoassay data were analyzed. The pituitary glands were removed at the end of experiment 3 , and the posterior lobe (with pars intermedia) was immediately separated and homogenized in $200 \mu \mathrm{l}$ of $0.14 \mathrm{M} \mathrm{HCl}$ in a $1 \mathrm{ml}$ glass minihomogenizer. The homogenates were frozen and lyophilized.

Radioimmunoassays. Push-pull perfusates as well as plasma samples were extracted as described previously, after lyophilized samples were first resuspended in assay buffer (Landgraf, 1981). Peptides in posterior pituitary homogenates were assayed without extraction.

Oxytocin content in the unextracted plasma samples from experiment 3 was measured in a single radioimmunoassay using the technique of Higuchi et al. (1985); sensitivity of this assay was $0.25 \mathrm{pg} /$ tube. In all the extracted samples, oxytocin and vasopressin contents were measured in specific radioimmunoassays as previously described (Landgraf, 1981); samples of one type from each experiment were measured in single assays. Sensitivity of this oxytocin assay was $0.3 \mathrm{pg} /$ tube, and of the vasopressin assay, $0.1 \mathrm{pg} /$ tube.

Statistics. Data were analyzed using paired Wilcoxon or Mann-Whitney $U$ tests for independent samples, following initial analysis of variance for repeated measures, and adjusting $p$ values for multiple comparisons where appropriate.

\section{Results}

\section{Central release of oxytocin and vasopressin in control rats}

In intracerebroventricular vehicle-infused rats, naloxone did not significantly increase oxytocin release in mediolateral septum, dorsal hippocampus, or nucleus of tractus solitarius (Figs. 1-3).

Vasopressin release was increased in the nucleus of tractus solitarius in the first perfusate after naloxone, but was not significantly affected in the mediolateral septum or dorsal hippocampus (Figs. 1-3).

Following histological examination of the push-pull cannula sites in the supraoptic nucleus group, these rats were divided into three subgroups (Figs. 4, 5): (1) those with cannula tips in or close to the supraoptic nucleus; (2) those with cannulas medial to the optic tract, in the supraoptico-paraventriculo-neurohypophysial tract (Armstrong et al., 1980); (3) those with cannulas placed more than approximately $500 \mu \mathrm{m}$ dorsal or caudal to the supraoptic nucleus and neurohypophysial tract (Moos et al., 1989). 
Figure 1. Release of oxytocin $(O X T)$ and vasopressin $(A V P)$ in mediolateral septum measured in three consecutive $30 \mathrm{~min}$ push-pull perfusates. Urethaneanesthetized rats, intracerebroventricular morphine (Mor) or vehicle (Veh) infusion for $5 \mathrm{~d}$; $n=$ number of rats. NALOXONE: $5 \mathrm{mg} / \mathrm{kg}$, intravenous. Values are mean $\pm \mathrm{SE} . *, p<0.02$ versus adjacent vehicle value ( $U$ test).
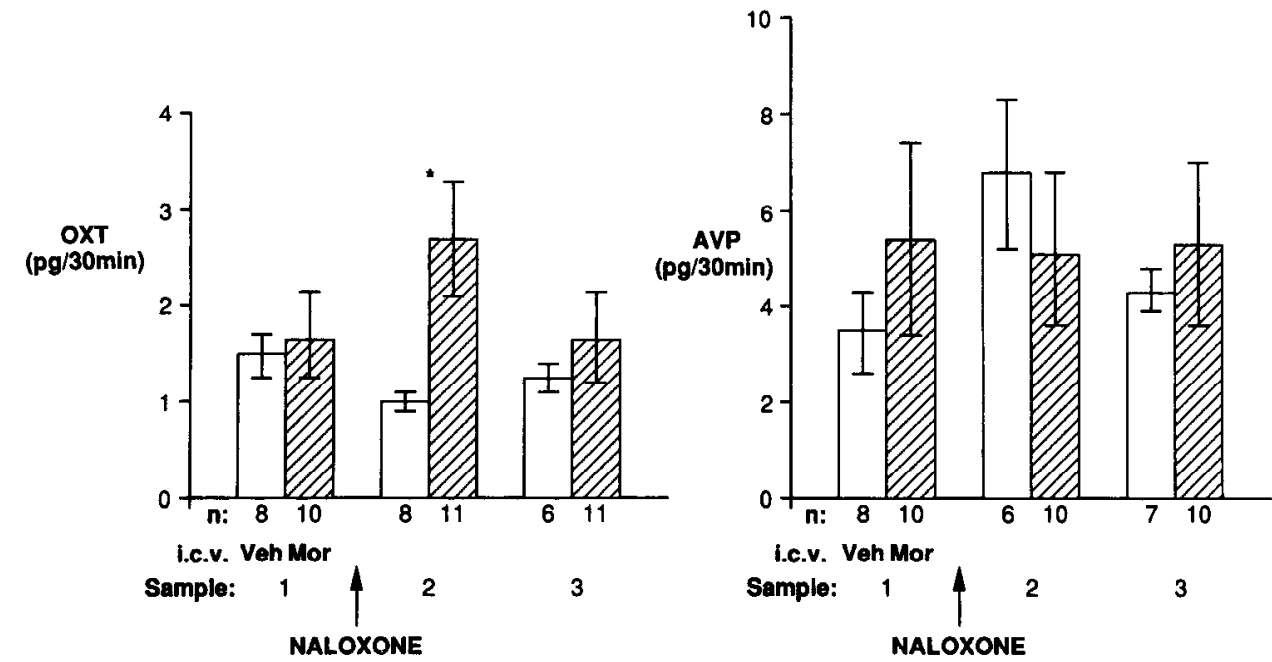

In intracerebroventricular vehicle-infused rats, naloxone did not increase oxytocin release at any of the sites related to the supraoptic nucleus, and had no significant effect on vasopressin release (Fig. 6).

\section{Central release of oxytocin and vasopressin in morphine- tolerant/dependent rats}

Before naloxone, release of oxytocin and vasopressin from the mediolateral septum, dorsal hippocampus, and nucleus of tractus solitarius in intracerebroventricular morphine-infused rats was similar to release from these sites in the control rats (Figs. $1-3)$. In the mediolateral septum, oxytocin release was increased in the first $30 \mathrm{~min}$ after naloxone, but only compared with the control group (Fig. 1); vasopressin release was not affected. Naloxone did not affect oxytocin or vasopressin release in dorsal hippocampus or the nucleus of tractus solitarius (Figs. 2, 3).

Before naloxone, release of oxytocin and vasopressin in all the supraoptic regions (see above, Fig. 6) was similar to release in the respective regions in control rats (Fig. 6).

Naloxone increased oxytocin release both from the supraoptic nucleus and from the supraoptico-neurohypophysial tract, but not from sites dorsal or caudal to the supraoptic nucleus (Fig.
6). In contrast, naloxone had no significant effect on vasopressin release from any of these sites (Fig. 6).

\section{Plasma oxytocin and vasopressin concentrations}

The combined data from the experiments in which the mediolateral septum, dorsal hippocampus, and supraoptic nuclei were perfused are shown in Figure 7. Before naloxone, plasma oxytocin was significantly less in the intracerebroventricular morphine-infused rats (Fig. 7) compared to the vehicle group. After naloxone, plasma oxytocin was increased 2.5-3-fold $(p<0.001)$ in the intracerebroventricular vehicle group for at least $60 \mathrm{~min}$, and in the intracerebroventricular morphine group plasma oxytocin was increased 36-fold after naloxone (Fig. 7; $p<0.001$ ). Plasma vasopressin concentration was also less in the intracerebroventricular morphine group before naloxone compared with the intracerebroventricular vehicle group (Fig. 7), but unlike oxytocin the secretion of vasopressin was unaffected by naloxone in the control group and was barely and briefly increased, but not above the control group value, by naloxone in the intracerebroventricular morphine group (Fig. 7).

In the group in which the nucleus of tractus solitarius was perfused, naloxone also increased oxytocin secretion more in
Figure 2. Release of oxytocin (OXT) and vasopressin $(A V P)$ in dorsal hippocampus. Details are as in Figure 1. No significant differences; two outlying oxytocin values in the intracerebroventricular vehicle group after naloxone are indicated (open circles).
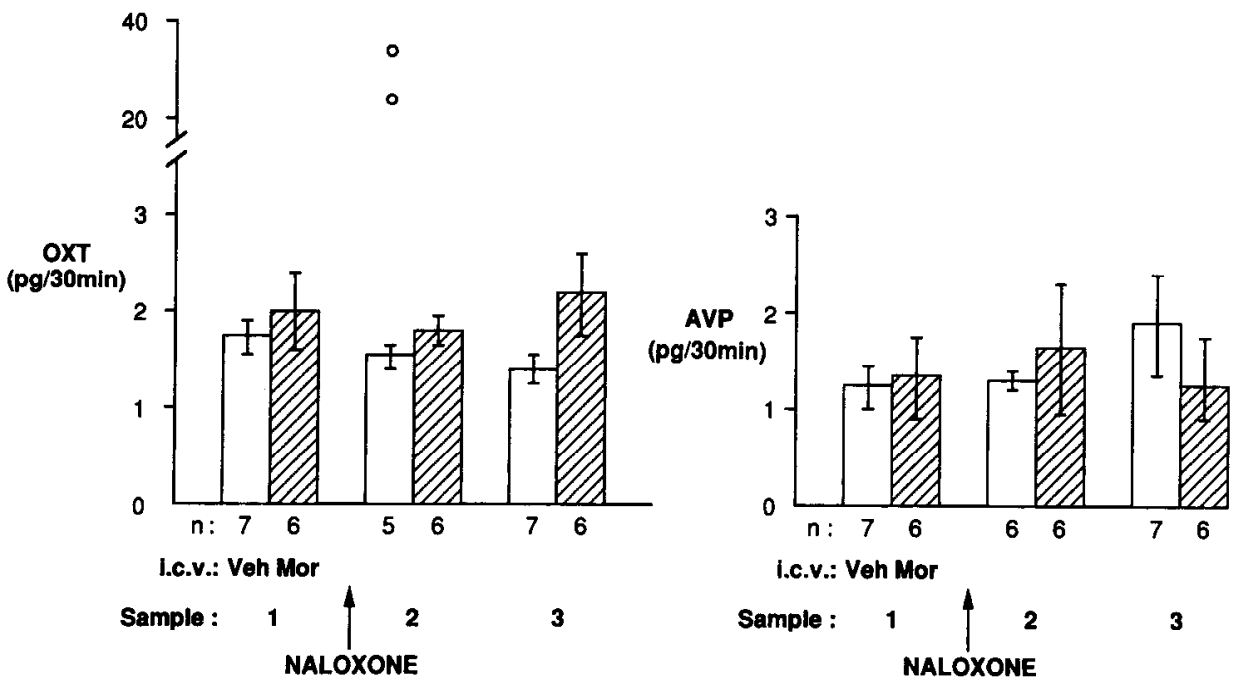


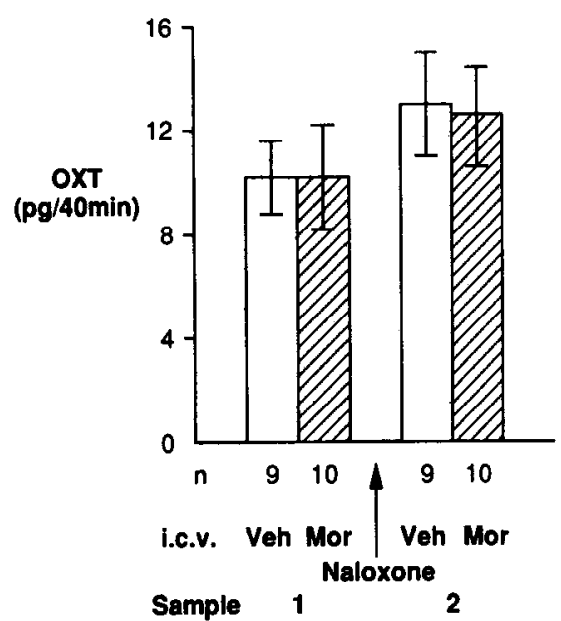

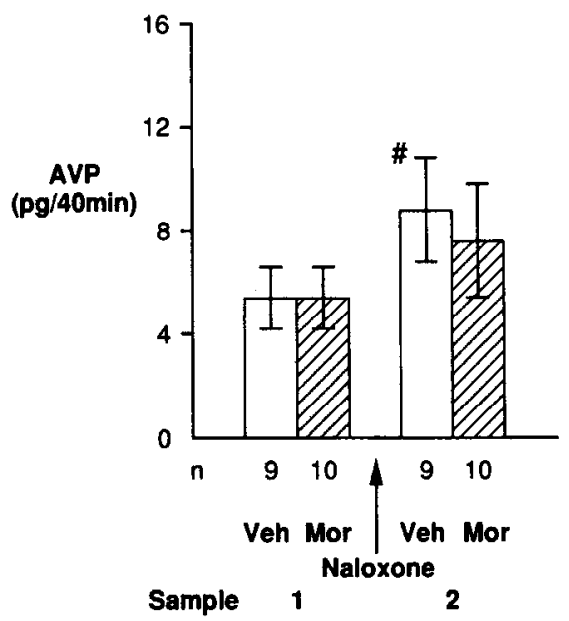

Figure 3. Release of oxytocin (OXT) and vasopressin $(A V P)$ in the nucleus of tractus solitarius; two consecutive 40 min push-pull perfusates. Details are as in Figure $1 . \#, p=0.05$ versus prenaloxone (paired Wilcoxon test).
A)

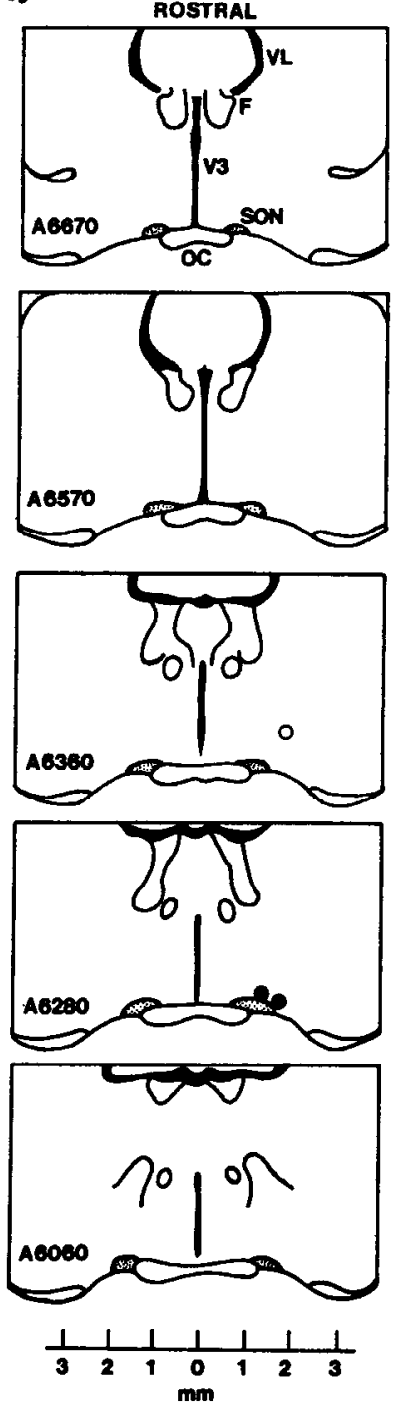

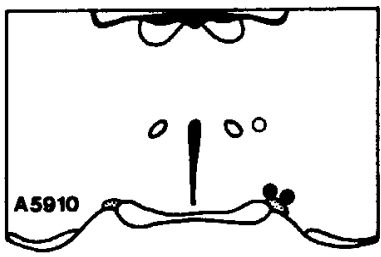
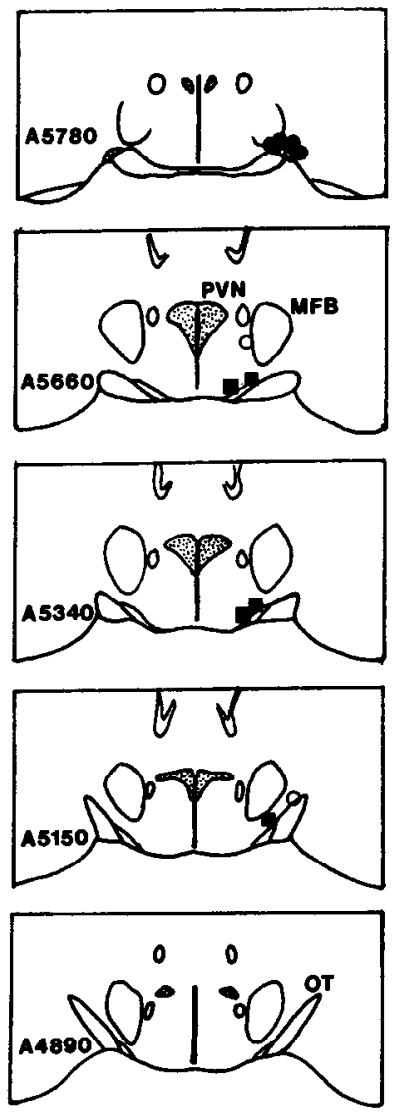

B)

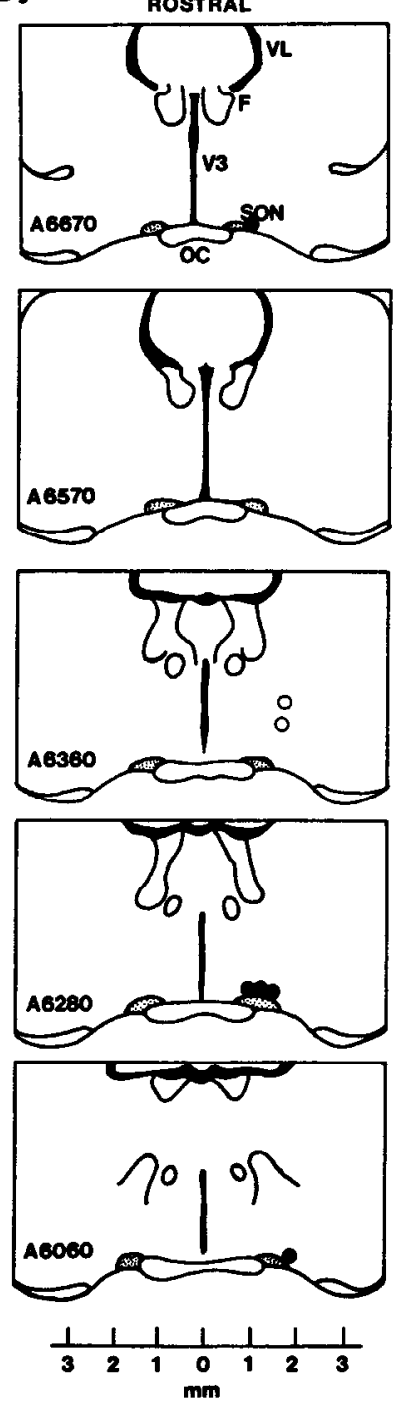

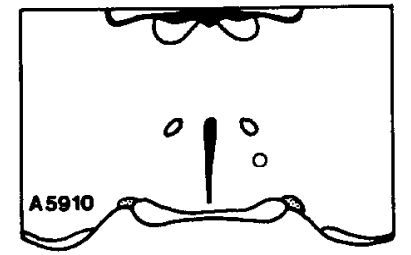
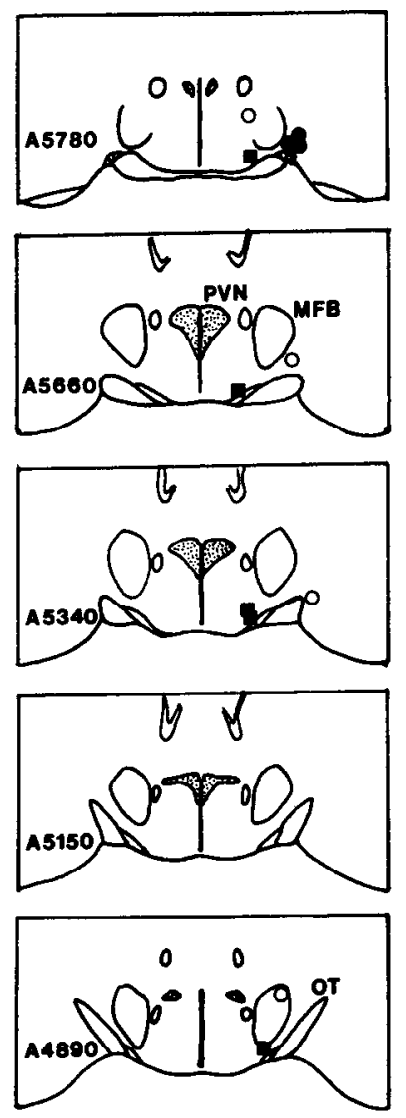

Figure 4. Diagrams of frontal sections through the hypothalamus to illustrate the locations of the push-pull perfusion cannula tip in the groups in which the supraoptic nucleus was the target. $A$, Intracerebroventricular vehicle-infused group; $B$, intracerebroventricular morphine-infused group. - Cannula tip in or cluse to the supraoptic nucleus (subgroup 1); $\square$, cannula tip medial to optic tract, adjacent to supraoptico-paraventriculoneurohypophysial tract (subgroup 2); O, cannula tip remote from supraoptic nucleus and neurohypophysial tract (subgroup 3). F, fornix; $M F B$, medial forebrain bundle; $O C$, optic chiasma; $O T$, optic tract; $P V N$, paraventricular nucleus; $S O N$, supraoptic nucleus; $V 3$, third ventricle; $V L$, lateral ventricle. The number at bottom left of each section is the distance in micrometers anterior to the interaural plane (after König and Klippel, 1963). 

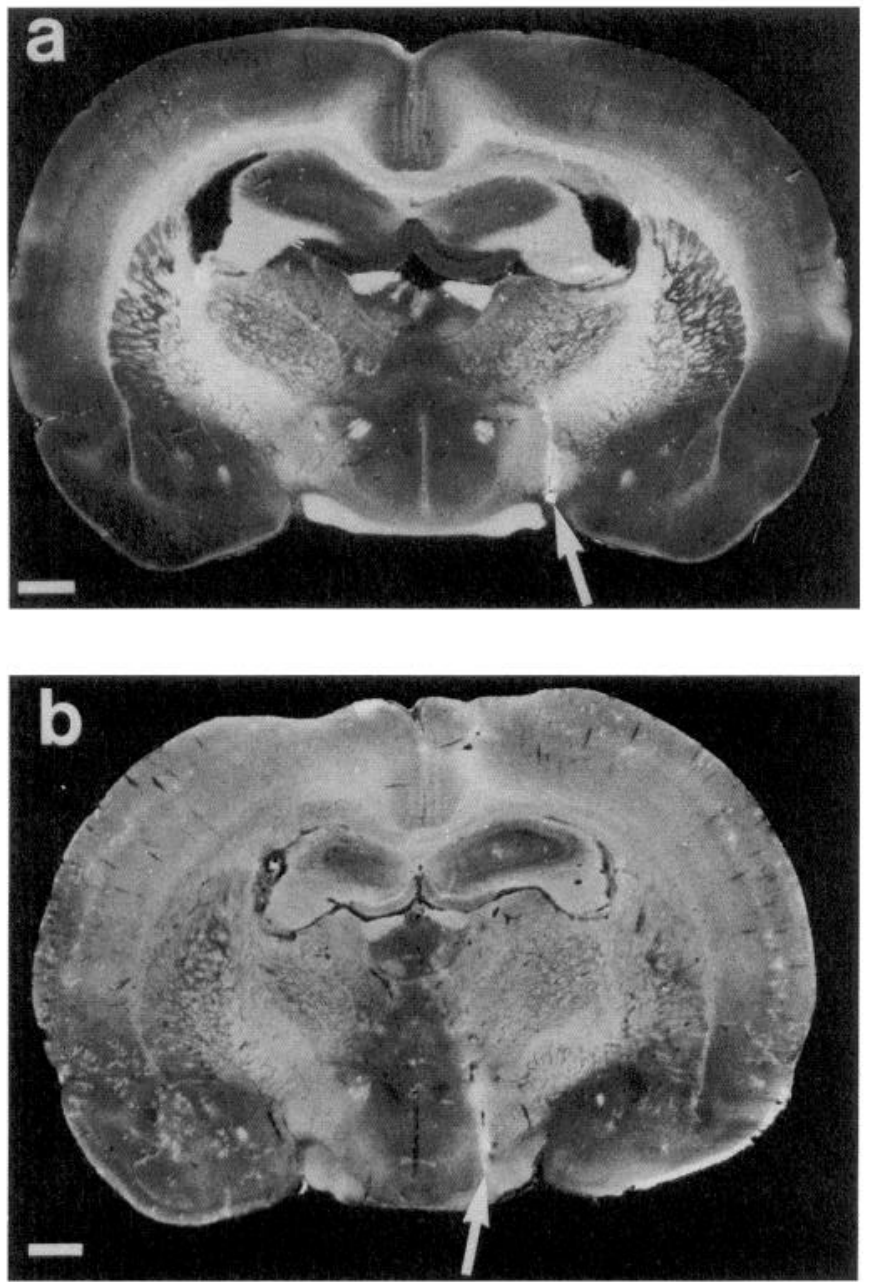

Figure 5. Photographs of $60 \mu \mathrm{m}$ frontal sections through the rostral hypothalamus to show typical position of push-pull perfusion cannulas (arrows) adjacent to the supraoptic nucleus (a) (see Fig. 4, subgroup 1) and medial to the optic tract $(b)$, adjacent to supraoptico-paraventriculoneurohypophysial tract (see Fig. 4, subgroup 2). Scale bar, $1 \mathrm{~mm}$.

the intracerebroventricular morphine group than in the intracerebroventricular vehicle group. The respective plasma oxytocin concentration values (mean $\pm \mathrm{SEM}$ ) in the intracerebroventricular vehicle group were, before naloxone, $20.2 \pm 5.3 \mathrm{pg} /$ $\mathrm{ml}(n=9)$ and, after naloxone, $77.8 \pm 29.6(n=9)$ and 79.0 $\pm 19.8(n=8) \mathrm{pg} / \mathrm{ml}$ (both $p<0.02$ vs. pre-naloxone). In the intracerebroventricular morphine group, the respective values were $12.6 \pm 3.7(n=10), 227 \pm 76(n=10)$, and $124 \pm 47(n$ $=10) \mathrm{pg} / \mathrm{ml}$; the latter values were significantly different from the pre-naloxone value (both $p<0.005$ ), and the first postnaloxone value was greater than the respective value in the intracerebroventricular vehicle group $(p<0.05)$.

\section{Posterior pituitary gland oxytocin and vasopressin contents}

After perfusion of the nucleus of tractus solitarius, in the intracerebroventricular vehicle group the posterior pituitary mean \pm SEM oxytocin content was $863 \pm 99 \mathrm{ng}(n=10)$ and the mean vasopressin content was $832 \pm 94 \mathrm{ng}(n=10)$. In the intracerebroventricular morphine group, posterior pituitary oxytocin content was $810 \pm 83 \mathrm{ng}(n=10)$ and vasopressin content was $861 \pm 69 \mathrm{ng}(n=10)$, not significantly different from values in the control group.

\section{Discussion}

In the morphine-tolerant/dependent rats, the mediolateral septum was the only site receiving projections from central oxytocin neurons in which oxytocin release showed any increase after naloxone, and this was only with respect to the control group. Together with the lack of effect of naloxone at this site in control rats, this result indicates that the oxytocin neurons projecting to the septum develop morphine dependence, and that acute morphine would be expected to inhibit these neurons. Oxytocin neurons projecting to dorsal hippocampus and the nucleus of tractus solitarius appear not to develop morphine dependence, since naloxone did not increase oxytocin release at these sites; this suggests that any opioids acting on these neurons would not do so via $\mu$-receptors. In the control rats, the lack of effect of naloxone indicates that endogenous opioids do not act on these neurons at all under urethane anesthesia; although time controls were not included in the present study, the lack of effect of naloxone is not likely to be due to diminishing peptide release from one push-pull perfusion period to the next (Landgraf et al., 1988; Neumann and Landgraf, 1989). Further experiments to study the acute effects of opioids on oxytocin release from central sites are required to test these conclusions. In striking contrast, during parturition (in conscious rats) but not afterward, naloxone increases oxytocin release in the mediolateral septum (Neumann et al., 1991), indicating a strong transient inhibitory action of endogenous opioids on oxytocin release in the septum at this time.

Naloxone had no effect on vasopressin release in the mediolateral septum, dorsal hippocampus, or nucleus of tractus solitarius in morphine-tolerant/dependent rats, demonstrating that vasopressin neurons projecting to these sites do not develop morphine dependence or, indeed, otherwise respond during morphine withdrawal. However, since in the control rats naloxone increased vasopressin release in the nucleus of tractus solitarius (but had no effects in the mediolateral septum or dorsal hippocampus), chronic morphine exposure may have induced tolerance to inhibitory action of endogenous opioids in control rats. Vasopressin neurons projecting to this site have their cell bodies in the posterior subdivision of the paraventricular nucleus (Buijs, 1978; Armstrong et al., 1980; Swanson and Kuypers, 1980). Endogenous opioids, including enkephalins produced by adjacent neurons, could affect the firing rate of these paraventricular nucleus neurons (Pittman et al., 1980), but presynaptic action on their terminals in the projection sites is also possible.

In control rats, the effects of naloxone on central oxytocin and vasopressin release differed from its effects on oxytocin and vasopressin secretion into the circulation. The lack of effect of naloxone on vasopressin secretion from the posterior pituitary gland indicates that it is not tonically influenced by endogenous opioids, whereas the increase in oxytocin secretion after naloxone shows that it is inhibited by endogenous opioids in urethane-anesthetized rats (Bicknell et al., 1988). The site of action of endogenous opioids on oxytocin secretion in this respect has been shown to be the posterior pituitary gland (Bicknell and Leng, 1982). The lack of effect of naloxone on central oxytocin release and its stimulation of oxytocin secretion into blood on one hand and the increase in central vasopressin release and lack of change in vasopressin secretion on the other provide further good evidence that the push-pull perfusion technique allows study of central oxytocin or vasopressin release without 

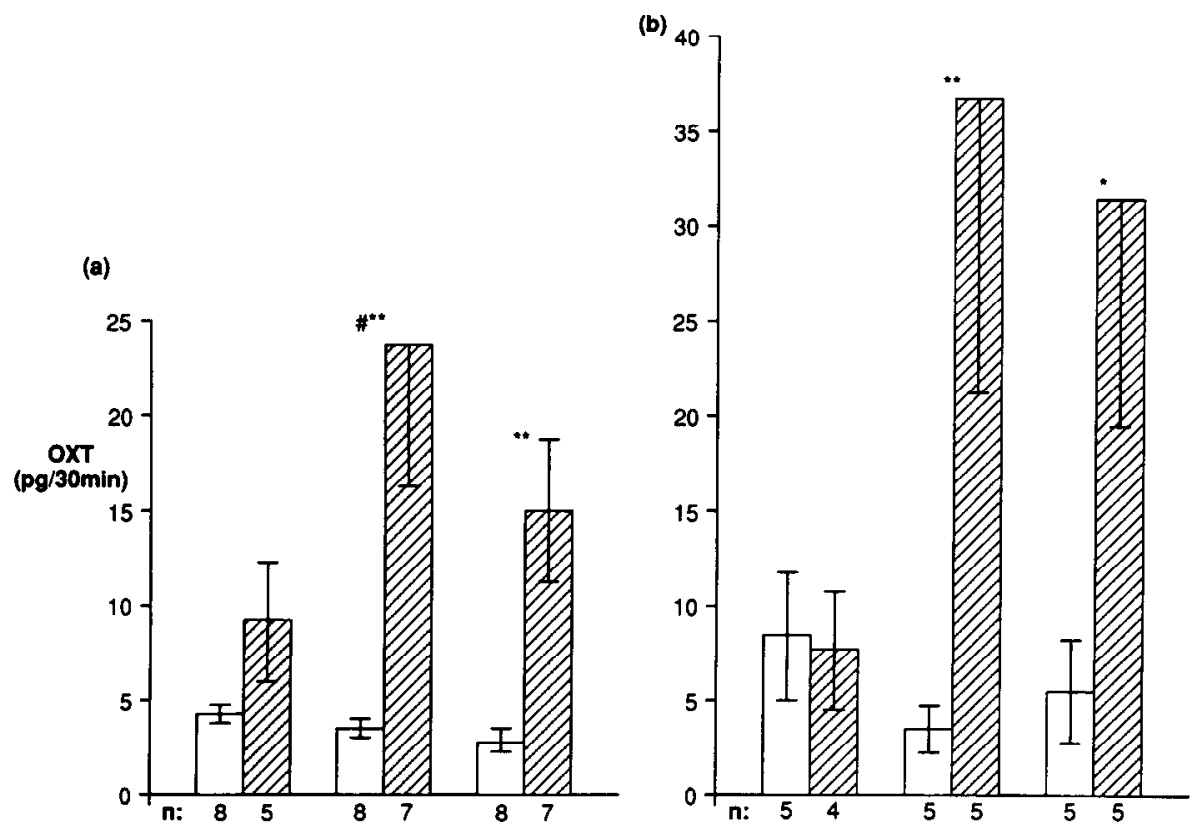

(c)
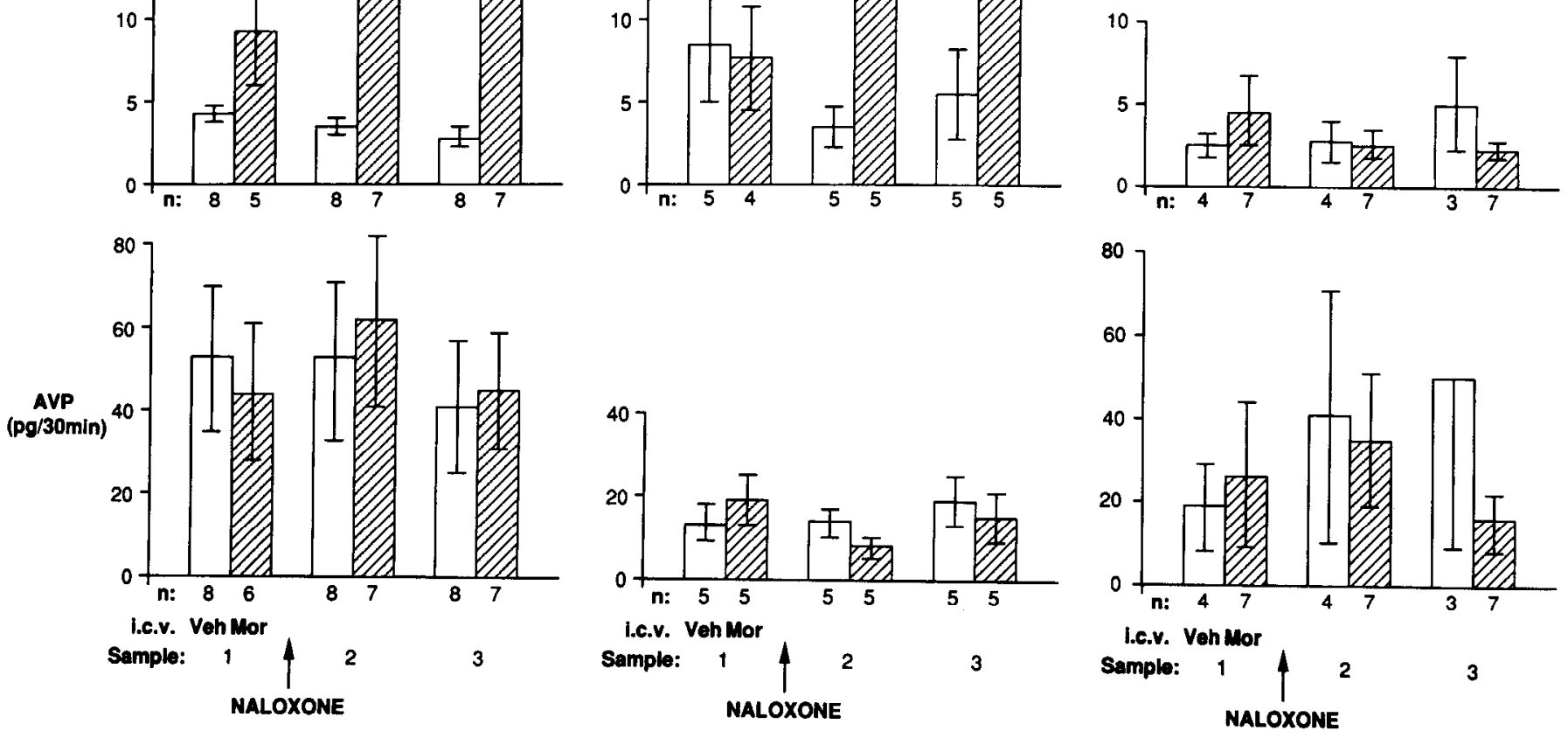

Figure 6. Central release of oxytocin $(O X T)$ and vasopressin $(A V P)$ from magnocellular neurons. Same rats and details as in Figure 1. $a$, Within the supraoptic nucleus (see Fig. 4); $b$, from the supraoptico-paraventriculo-neurohypophysial tract; $c$, dorsal/lateral to supraoptic nucleus (off target). Values are mean $\pm \mathrm{SE} .{ }^{*}, p<0.05$ and ${ }^{* *}, p<0.01$ versus adjacent vehicle value ( $U$ test); $\#, p<0.05$ versus pre-naloxone value (paired Wilcoxon test).

contamination by circulating peptide (Landgraf et al., 1988; Neumann and Landgraf, 1989).

There is electrophysiological, microanatomical, and electron microscopic evidence, as well as evidence from measurement of peptide release from hypothalamic slices or microdissected supraoptic nuclei in vitro, that oxytocin and vasopressin are released from the dendrites and axon processes of the magnocellular neurons that primarily secrete these peptides from their endings in the posterior pituitary (Mason et al., 1984, 1986; Moos et al., 1984; Morris and Pow, 1988; Pow and Morris, 1989). In vitro studies have shown that vasopressin release substantially exceeds that of oxytocin (Moos et al., 1984; Mason et al., 1986), and we found a similar excess of vasopressin relative to oxytocin in the present in vivo study; in blood plasma, oxytocin concentration was greater than that of vasopressin, and this strongly suggests that peptides recovered by push-pull perfusion of the supraoptic nucleus are released there and have not crossed from the blood. In control animals, naloxone did not significantly affect vasopressin release in the supraoptic nucleus, and the delayed small decrease in oxytocin release after naloxone may have been related to the duration of perfusion. The results indicate that, in contrast to the situation in the posterior pituitary, the release of oxytocin in the supraoptic nuclei is not inhibited by endogenous opioids during urethane anesthesia, and this accords with the lack of effect of naloxone on the firing rate of supraoptic oxytocin neurons in these conditions (Bicknell et al., 1988). However, the firing rate of magnocellular oxytocin neurons in morphine-tolerant/dependent rats is increased about 3.5-fold by naloxone (Bicknell et al., 1988; Leng et al., 1989; Pumford et al., 1991), and as previously reported, this leads to the much greater increase in oxytocin concentration in peripheral blond after naloxone in morphine-tolerant/dependent rats than in the controls (Bicknell et al., 1988; Sumner et al., 1989), and similar results in the present study confirm morphine dependence. The increase in firing rate of magnocellular oxytocin neurons during naloxone-precipitated morphine withdrawal also could explain the sustained increase in oxytocin release in the supraoptic nucleus after naloxone, probably from the dendrites of supraoptic neurons (Pow and Morris, 1989); the relatively smaller increase in oxytocin release from the supraoptic nuclei 

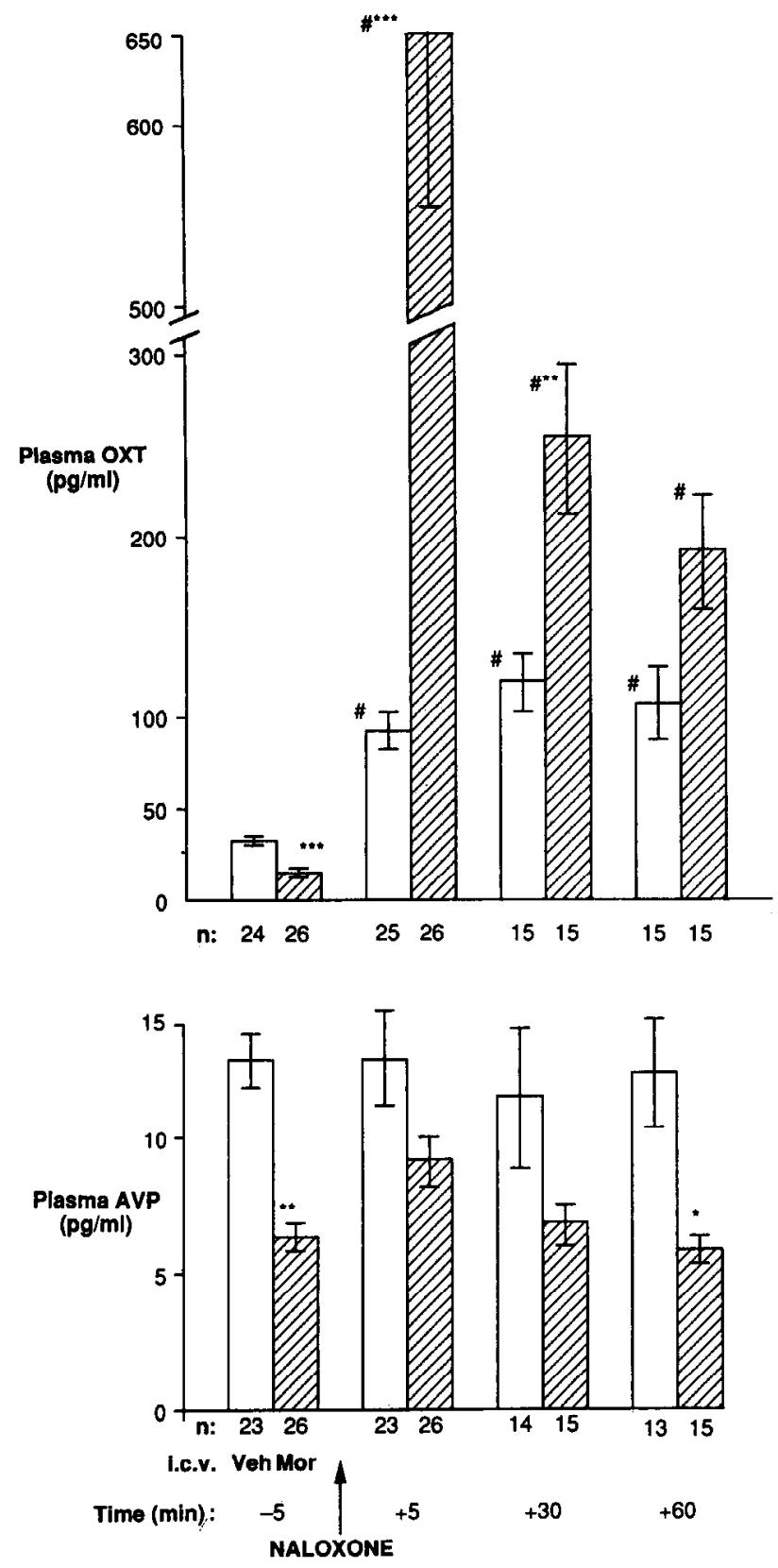

Figure 7. Plasma oxytocin ( $O X T)$ and vasopressin (AVP) concentrations: combined data from rats in Figures 1 and 2 . Veh, Intracerebroventricular vehicle; $M o r$, intracerebroventricular morphine for $5 \mathrm{~d}$. Values are mean $\pm \mathrm{SE} . *, p<0.05,{ }^{* *}, p<0.02$, and ${ }^{* * *}, p<0.001$ versus adjacent intracerebroventricular vehicle group ( $U$ test); \#, $p<0.001$ versus respective pre-naloxone (paired Wilcoxon test).

than from the postcrior pituitary during morphine withdrawal is readily explained by lack of the additional amplification that results from antagonizing inhibitory endogenous opioid restraint in the posterior pituitary (Bicknell et al., 1988); however, compared with the post-naloxone values in the control group, the relative increase in central oxytocin release and oxytocin secretion from the posterior pituitary was similar, six- to sevenfold, consistent with similar release mechanisms in the dendrites and axon terminals.

Although stimulated release of both vasopressin and oxytocin from the supraoptic nucleus and of vasopressin from magno- cellular axons in the median eminence is $\mathrm{Ca}^{2+}$ dependent (Moos et al., 1984; Holmes et al., 1986; Mason et al., 1986; Di Scala et al., 1987; Pow and Morris, 1989; Landgraf et al., in press), basal release of oxytocin from the supraoptic nucleus may not be (Moos et al., 1984; Mason et al., 1986), so the $\mathrm{Ca}^{2+}$-dependent increase in oxytocin release from the supraoptic regions during morphine withdrawal may be underestimated. Since oxytocin itself can excite magnocellular oxytocin neurons (Moos et al., 1984; Yamashita et al., 1987), its increased release in the supraoptic nucleus during morphine withdrawal may well contribute to the excitation of magnocellular oxytocin neurons in this state. Oxytocin release was also strikingly increased during withdrawal at perfusion sites medial to the optic tracts, where there are very few oxytocin perikarya (Rhodes et al., 1981), and this oxytocin is probably released from axon swellings of magnocellular oxytocin neurons (Armstrong et al., 1980; Holmes et al., 1986; Buma and Nieuwenhuys, 1987, 1988), or perhaps from damaged axons, as more action potentials pass along the axons after naloxone (Bicknell et al., 1988). Oxytocin released centrally by supraoptic neurons may enter the CSF in the third ventricle and account for the increased oxytocin level in cisterna magna CSF seen during morphine withdrawal (Coombes et al., 1988, 1991).

The increased release of oxytocin in the supraoptic nucleus during morphine withdrawal indicates that the initial action of morphine on oxytocin release in the supraoptic nucleus would be inhibitory; certainly, acute morphine has been shown to inhibit the firing of supraoptic oxytocin neurons potently in vivo and in vitro (Wakerley et al., 1983; Pumford et al., 1991) and to reduce oxytocin secretion in vivo (Evans et al., 1989; Pumford et al., 1991), although its effects on oxytocin release within the nucleus have not been studied. If morphine does inhibit oxytocin release in the supraoptic nucleus, then tolerance seems to develop during chronic intracerebroventricular morphine infusion since there were no differences before naloxone between control and morphine-tolerant/dependent rats. In other studies, tolerance has been found to develop for the inhibitory action of morphine on the firing rate of magnocellular oxytocin neurons (Russell, 1989; Pumford et al., 1991); such tolerance is incomplete, as indicated in the present study by the lower concentration of oxytocin in peripheral blood before naloxone in the morphine-tolerant/dependent rats than in the controls. Unlike oxytocin, the secretion of vasopressin in morphine-tolerant/ dependent rats is barely increased by naloxone, as confirmed in the present study, and there is no consistent increase in the firing rate of vasopressin neurons (Bicknell et al., 1988). The lack of increase in vasopressin release in the supraoptic nucleus or at the perfusion sites medial to the optic tracts after naloxone in the morphine-treated rats is consistent with the lack of excitation of the firing rate of vasopressin neurons. Lower pre-naloxone vasopressin levels in the circulation before naloxone in the morphine-treated rats could reflect lack of tolerance to an inhibitory action of morphine on vasopressin secretion (Aziz et al., 1981), although it is not clear why this was not fully reversed by naloxone (see Bicknell et al., 1988).

In conclusion, in urethane-anesthetized, vehicle-treated rats, in contrast to the inhibitory action of endogenous opioids on oxytocin secretion from the posterior pituitary gland, endogenous opioids do not actively inhibit the release of oxytocin from terminals in the mediolateral septum, dorsal hippocampus, and nucleus of tractus solitarius or from the dendrites and axons of magnocellular supraoptic neurons. Vasopressin release in the 
nucleus of tractus solitarius is increased after naloxone, indicating endogenous opioid inhibition of vasopressin release at this site, which contrasts with the lack of endogenous opioid inhibition of vasopressin secretion from the posterior pituitary gland.

In morphine-tolerant/dependent rats, among the centrally projecting oxytocin neurons, only those with terminals in the mediolateral septum differed from controls, and none of the centrally projecting vasopressin neurons responded. This selective enhancement of oxytocin release in the mediolateral septum resembles the effects of naloxone during parturition (Neumann et al., 1991) and suggests that increased oxytocin release in septum after naloxone during parturition reflects withdrawal from a transient endogenous opioid inhibition at this time. The largest increase in central oxytocin release during morphine withdrawal was seen from the dendrites, axons, or cell bodies of supraoptic magnocellular neurons, and this may be the source of increased oxytocin in CSF during morphine withdrawal (Coombes et al., 1988, 1991); the increased release of oxytocin from magnocellular neuron axons or dendrites could also account for increased oxytocin content in hypothalamo-hypophysial portal blood during morphine withdrawal (Sheward et al., 1990).

\section{References}

Armstrong WE, Warach S, Hatton GI, McNeill TH (1980) Subnuclei in the rat hypothalamic paraventricular nucleus: a cytoarchitectural, horseradish peroxidase and immunocytochemical analysis. Neuroscience 5:1931-1958.

Aziz LA, Forsling ML, Woolf CJ (1981) The effect of intracerebroventricular injections of morphine on vasopressin release in the rat. J Physiol (Lond) 31 1:401-409.

Bicknell RJ, Leng G (1982) Endogenous opiates regulate oxytocin but not vasopressin secretion from the neurohypophysis. Nature 298: 161-162.

Bicknell RJ, Leng G, Lincoln DW, Russell JA (1988) Naloxone excites oxytocin neurones in the supraoptic nucleus of lactating rats after chronic morphine treatment. J Physiol (Lond) 396:297-317.

Buijs RM (1978) Intra- and extrahypothalamic vasopressin and oxytocin pathways in the rat. Cell Tissue Res 192:423-425.

Buijs RM, van Heerikhuize JJ (1982) Vasopressin and oxytocin release in the brain - a synaptic event. Brain Res 252:71-76.

Buijs RM, de Vries GJ, van Leeuwen FW (1985) The distribution and synaptic release of oxytocin in the central nervous system. In: Oxytocin: clinical and laboratory studies (Amico JA, Robinson AG, eds), pp 77-86. Amsterdam: Elsevier.

Buma P, Nieuwenhuys R (1987) Ultrastructural demonstration of oxytocin and vasopressin release sites in the neural lobe and median eminence of the rat by tannic acid and immunogold methods. Neurosci Lett 74:151-157.

Buma P, Nieuwenhuys R (1988) Ultrastructural characterization of exocytotic release sites in different layers of the median cminence of the rat. Cell Tissue Res 252:107-114.

Caldwell JD, Greer ER, Johnson MF, Prange AJ Jr, Pedersen CA (1989) Oxytocin and vasopressin immunoreactivity in hypothalamic and extrahypothalamic sites in late pregnant and postpartum rats. Neuroendocrinology 46:39-47.

Coombes JE, Robinson ICAF, Russell JA (1988) Release of oxytocin (OXT) into both cerebrospinal fluid (CSF) and blood by naloxone in anaesthetized morphine-dependent rats. J Physiol (Lond) 398:79P.

Coombes JE, Robinson ICAF, Antoni FA, Russell JA (1991) Release of oxytocin into blood and into cerebrospinal fluid induced by naloxone in anaesthetized morphine-dependent rats: the role of the paraventricular nucleus. J Neuroendocrinol 3:551-561.

Di Scala-Guenot D, Strosser MT, Richard P (1987) Electrical stimulations of perifused magnocellular nuclei in vitro elicit $\mathrm{Ca}^{2+}$-dependent, tetrodotoxin-insensitive release of oxytocin and vasopressin. Neurosci Lett 76:209-214.

Evans RG, Olley JE, Rice GE, Abrahams JM (1989) Mu-and k-opiate receptor agonists reduce plasma neurohypophysial hormone concen- trations in water-deprived and normally-hydrated rats. Clin Exp Pharmacol Physiol 16:191-197.

Freund-Mercier MJ, Richard P (1984) Electrophysiological evidence for facilitatory control of oxytocin neurones by oxytocin during suckling in the rat. J Physiol (Lond) 352:447-466.

Freund-Mercier MJ, Moos F, Poulain DA, Richard P, Rodriguez R, Theodosis DT, Vincent JD (1988) Role of central oxytocin in the control of the milk ejection reflex. Brain Res Bull 20:737-741.

Higuchi T, Honda K, Fukuoka T, Negoro H, Wakabayashi K (1985) Release of oxytocin during suckling and parturition in the rat. J Endocrinol 105:339-346.

Holmes MC, Antoni FA, Aguilera G, Catt KJ (1986) Magnocellular axons in passage through the median eminence release vasopressin. Nature 319:326-329.

Jones PM, Robinson ICAF, Harris MC (1983) Release of oxytocin into blood and cerebrospinal fluid by electrical stimulation of the hypothalamus or neural lobe in the rat. Neuroendocrinology 37:454458.

König JFR, Klippel RA (1963) 'The rat brain: a stereotaxic atlas. Baltimore: Williams \& Wilkins.

Landgraf R (1981) Simultaneous measurement of arginine vasopressin and oxytocin in plasma and neurohypophyses by radioimmunoassay. Endokrinologie 78:191-204.

I andgraf R, Neumann I, Schwarzberg H (1988) Central and peripheral release of vasopressin and oxytocin in the conscious rat after osmotic stimulation. Brain Res 457:219-225.

Landgraf R, Malkinson T, Horn T, Veale WL, Lederis K, Pittman QJ (1990) Release of vasopressin and oxytocin by paraventricular stimulation in rats. Am J Physiol 258:R155-R159.

Landgraf R, Neumann I, Russell JA, Pittman QJ (in press) Push-pull perfusion and microdialysis studies of central oxytocin and vasopressin release in freely moving rats during pregnancy, parturition and lactation. Ann NY Acad Sci, in press.

Leng G, Russell JA, Grossmann R (1989) Sensitivity of magnocellular oxytocin neurones to opioid antagonists in rats treated chronically with intracerebroventricular (i.c.v.) morphine. Brain Res 484:290296.

Mason WT, Ho YW, Hatton GI (1984) Axon collaterals of supraoptic neurones: anatomical and electrophysiological evidence for their existence in the lateral hypothalamus. Neuroscience 11:169-182.

Mason WT, Hatton GI, Ho YW, Chapman C, Robinson ICAF (1986) Central release of oxytocin, vasopressin and neurophysin by magnocellular neurone depolarization: evidence in slices of guinea pig and rat hypothalamus. Neuroendocrinology 42:31 1-322.

Moos F, Freund-Mercier JJ, Guerne Y, Guerne JM, Stoeckel ME, Richard $\mathbf{P}$ (1984) Release of oxytocin and vasopressin by magnocellular nuclei in vitro: specific facilitatory effect of oxytocin on its own release. J Endocrinol 102:63-72.

Moos F, Poulain DA, Rodriguez F, Guerne Y, Vincent JD, Richard P (1989) Release of oxytocin within the supraoptic nucleus during the milk ejection reflex in rats. Exp Brain Res 76:593-602.

Morris JF, Pow DV (1988) Capturing and quantifying the exocytotic event. J Exp Biol 139:81-103.

Neumann I, Landgraf R (1989) Septal and hippocampal release of oxytocin, but not vasopressin, in the conscious lactating rat during suckling. J Neuroendocrinol 1:305-308.

Neumann I, Schwarzberg H, Landgraf R (1988) Measurement of septal release of vasopressin and oxytocin by the push-pull technique following electrical stimulation of the paraventricular nucleus of rats. Brain Res 462:181-184.

Neumann I, Russell JA, Wolff B, Landgraf R (1991) Naloxone increases the release of oxytocin, but not vasopressin, within limbic brain areas of conscious parturient rats: a push-pull perfusion study. Neuroendocrinology 54:545-551.

Paxinos G, Watson C (1982) The rat brain in stereotaxic coordinates. Sydney: Academic.

Pittman QJ, Hatton JD, Bloom FE (1980) Morphine and opioid peptides reduce paraventricular neuronal activity: studies on the rat hypothalamic slice preparation. Proc Natl Acad Sci USA 77:5527-5531.

Pow DV, Morris JF (1989) Dendrites of hypothalamic magnocellular neurons release neurohypophysial peptides by exocytosis. Neuroscience 32:435-440.

Pumford K, Leng G, Russell JA (1991) Morphine actions on supraoptic oxytocin neurones in anaesthetized rats: tolerance after i.c.v. morphine-infusion. J Physiol (Lond) 440:437-454. 
Rayner VC, Robinson ICAF, Russell JA (1988) Chronic intracerebroventricular morphine and lactation in rats: dependence and tolerance in relation to oxytocin neurones. J Physiol (Lond) 396:319 347.

Rhodes CH, Morrell JI, Pfaff DW (1981) Immunohistochemical analysis of magnocellular elements in rat hypothalamus: distribution and numbers of cells containing neurophysin, oxytocin and vasopressin. J Comp Neurol 198:45-64.

Robinson ICAF (1983) Neurohypophysial peptides in cerebrospinal fluid. In: Progress in brain research, Vol 60, The neurohypophysis: structure, function and control (Cross BA, Leng G, eds), pp 129-145. Amsterdam: Elsevier.

Russell JA (1989) Opiate dependence and tolerance in oxytocinergic neurones. J Biomed Res 10 [Suppl 3]:95-106.

Russell JA, Neumann I, Landgraf R (1990) Push-pull perfusion study of oxytocin release in discrete brain regions after naloxone in morphine-dependent urethane-anaesthetized rats. In: Abstracts of the European Society for Neurochemistry 8th general meeting, $p 142$.

Sawchenko PE, Swanson LW (1985) Relationship of oxytocin pathways to the control of neuroendocrine and autonomic function. In: Oxytocin: clinical and laboratory studies (Amico JA, Robinson AG, eds), pp 87-103. Amsterdam: Elsevier.

Sheward WJ, Coombes JE, Bicknell RJ, Fink G, Russell JA (1990) Release of oxytocin but not corticotrophin-releasing factor- 41 into rat hypophysial portal vessel blood can be made opiate dependent. J Endocrinol 124:141-150.

Sofroniew MV (1983) Morphology of vasopressin and oxytocin neurones and their central and vascular projections. In: Progress in brain research, Vol 60, The neurohypophysis: structure, function and control (Cross BA, Leng G, eds), pp 101-122. Amsterdam: Elsevier.

Sumner BEH, Kawata M, Russell JA (1989) Does acute, intense stimulation of oxytocin neurones in the supraoptic nucleus increase their content of oxytocin mRNA? Brain Res 489:283-290.

Swanson LW, Kuypers HGJM (1980) The paraventricular nucleus of the hypothalamus: cytoarchitectonic subdivisions and organization of projections to the pituitary, dorsal vagal complex and spinal cord as demonstrated by retrograde fluorescence double-labelling methods. J Comp Neurol 194:555-570.

van Leengoed E, Kerker E, Swanson HH (1987) Inhibition of postpartum maternal behaviour in the rat by injecting an oxytocin antagonist into the cerebral ventricles. J Endocrinol 112:275-282.

Wakerley JB, Noble R, Clarke G (1983) Effects of morphine and D-Ala-D-Leu enkephalin on the electrical activity of supraoptic neurosecretory cells in vitro. Neuroscience 10:73-81.

Yamashita H, Okuya H, Inenaga K, Kasai M, Uesugi S, Kannan H, Kaneuko T (1987) Oxytocin predominantly excites putative oxytocin neurones in the rat supraoptic nucleus in vitro. Brain Res 416: 364-368. 